\title{
Julia Kapelańska-Pręgowska*
}

\section{LAWS GOVERNING POSTNATAL GENETIC TESTING FOR MEDICAL PURPOSES \\ IN GERMANY, SWITZERLAND, SPAIN AND FRANCE}

\begin{abstract}
Genetic testing is slowly becoming an integral part of general health services, changing our understanding of "illness" and "being healthy", and bringing new challenges for various actors: patients, doctors, insurers and policy-makers. The question is, how the law should respond to the genetic advances and their applications in clinical practice, in order to maximise their benefits and minimise risks. The aim of the article is to present, analyse and compare laws on genetic testing adopted in Germany, Switzerland, Spain and France. This "horizontal" comparative perspective will be complemented to some extent with a "vertical" one - in order to identify parallels and major differences between the analysed domestic regulations and international standards (especially with the $I V^{\text {th }}$ Additional Protocol to the European Convention on Human Rights and Biomedicine).
\end{abstract}

Keywords

genetic data - national legislation - role of international standards - consent - types of genetic tests - duty to warn - DTC testing

Juris Doctor (2010), Assistant Professor at the Human Rights Department of the Faculty of Law and Administration, Nicolaus Copernicus University. 


\section{INTRODUCTION}

Genetic tests were recently brought to the attention of global public opinion by the decision of a famous actress - Angelina Jolie - to do a BRCA test, and subsequently, to undergo a preventive double mastectomy. Jolie's case appeared in countless headlines and was commented on by many specialists and ordinary citizens. Even though the media are already engaged with other topics, we may hope that regulating genetic testing will remain on the policy-makers' agenda.

Since 2003, when the Human Genome Project had been successfully completed $^{1}$, genetic testing has been slowly becoming an integral part of general health services. It has been argued that the development of genetics in health care services will have a major impact on the organisation of health care, leading to a shifting from curative to preventive services. What seems to be a major concern today, is providing equitable access to genetic services and follow-up treatment ${ }^{2}$.

The question of how the law should respond to genetic advances and their applications in clinical practice has been raised by a number of advisory bodies and scholars representing different disciplines of science, especially law, ethics, and medicine ${ }^{3}$. The debate has often been focused around the question of "genetic exceptionalism" and privacy issues", nevertheless the discussion on if and how to regulate genetic

1 Project's aim was to read a whole human genome sequence. More about the Project at: http://www.genome.gov.

2 Recommendation $\mathrm{CM} / \operatorname{Rec}(2010) 11$ of the Committee of Ministers to Member States on the impact of genetics on the organisation of health care services and training of health professionals, adopted by the Committee of Ministers of the Council of Europe on 29.09.2010.

3 See i.a.: International Bioethics Committee, I.A. Motoc, Interim Report: Human Rights and a Human Genome, 14.07.2005, E/CN.4/Sub.2/2005/38; International Bioethics Committee, R/99/CIB-6/GT-2/3, Report on Confidentiality and Genetic Data, 2000, BIO-503; UNESCO, A. Shapiro, Report on Genetic Screening and Testing, 1994, SHS-94/CONF.011/7; European Commission, The Independent Expert Group (E. McNally, A. Cambon-Thomsen et al.), Ethical, Legal and Social Aspects of Genetic Testing: Research, Development and Clinical Applications, Brussels: European Commission 2004; G. Laurie, Genetic Privacy: A Challenge to Medico-Legal Norms, Cambridge: Cambridge University Press 2002; J. Kapelańska-Pręgowska, Prawne i bioetyczne aspekty testów genetycznych [Legal and Bioethical Aspects of Genetic Testing], Warszawa: Wolters Kluwer 2011.

4 A. Krajewska, Conceptual Quandaries about Genetic Data - A Comparative Perspective, European Journal of Health Law 2009, vol. 16, pp. 7-26; J.H. Gerards, Genetic Issues Concerning Genetic Information, [in:] J.H. Gerards, A.W. Heringa, L. Janssen, Genetic Discrimination 
testing is much more complex. It seems that over the years, both the doctrine and policymakers - aware of the rapid progress in genetics - have agreed that a normative answer to the problem is necessary for very pragmatic reasons. The question remains how to do it best?

The complexity of the subject matter results, to a great extent, from two aspects: the specificity of different types of tests and the familial character of genetic information. Laws governing genetic testing should be precise enough to address these problems in order to explore the benefits of genetics in the field of health and to avoid or minimise potential risks.

Genetic tests make it possible to diagnose or to confirm the diagnosis in a person already presenting symptoms. But they also make possible the identification of genetic mutations responsible for a disease which only develops later in life, or of a predisposition to a disease before symptoms appear. Early identification of genetic characteristics by a test can present a health benefit, if it makes it possible to take preventive measures or to limit the risks by modifying the behaviour, life style or environment of the person concerned.

However, we also need to acknowledge concerns raised regarding possible improper uses of the information generated by genetic testing. Results of genetic analysis are often complex and a proper understanding of their implications is, in many cases, difficult for the persons concerned. Recently, the German Ethics Council has identified three major ethical challenges caused by the rapidly growing quantity of collectable genetic information and access to this information (i.a. through direct commercial offers for genetic tests outside any health system). According to the Council, the three ethical problem areas are: questions of the understanding of illness and death; issues

and Genetic Privacy in Comparative Perspective, Antwerp/Oxford/New York: Intersentia 2005, pp. 15-22; T.H. Murray, Genetic Exceptionalism and 'Future Diaries': Is Genetic Information Different From Other Medical Information, [in:] M.A. Rothstein (ed.), Genetic Secrets. Protecting Privacy and Confidentiality in the Genetic Era, New Haven-London: Yale University Press 1997, p. 61. 
of autonomy, self-determination and responsibility; social aspects: justice and solidarity 5 .

These concerns, as well as the predicted widespread use of genetic testing in the near future, have induced number European governments to propose a normative answer. Some states have decided to regulate only some aspects of genetic testing within an existing legal framework (within laws governing protection of personal data or patients rights, etc.) ${ }^{6}$. There are however a few states that opted for a comprehensive regulation of biomedical advances in general or genetic technology in specific; that is - Austria (Law on genetic engineering of 1994) ${ }^{7}$, France (Law on bioethics of 2004) ${ }^{8}$, Germany (Law on genetic diagnosis of 2009) ${ }^{9}$, Portugal (Law on personal genetic and medical information of 2005) ${ }^{10}$, Spain (Law on biomedical research) ${ }^{11}$, Switzerland (Federal law on genetic analysis of 2004) ${ }^{12}$, Sweden (Law on genetic integrity of 2004) ${ }^{13}$ and Norway (Law on biotechnology of 2003) ${ }^{14}$.

The aim of the article is to present, analyse and compare laws on genetic testing adopted in Germany, Switzerland, Spain and France. This "horizontal" comparative perspective will be complemented to some

5 Ethikrat OPINION: The Future of Genetic Diagnosis - From Research to Clinical Practice, Berlin 30.04.2010, p. 104. Available in German and English at: http://www.ethikrat.org [last accessed: 21.12.2013].

6 Kapelańska-Pręgowska, supra note 3, pp. 296-297.

7 Gentechnikgesetz, BGBl. Nr. 510/1994. Full name of the act: Bundesgesetz, mit dem Arbeiten mit gentechnisch veränderten Organismen, das Freisetzen und Inverkehrbringen von gentechnisch veränderten Organismen und die Anwendung von Genanalyse und Gentherapie am Menschen geregelt werden (Gentechnikgesetz - GTG) und das Produkthaftungsgesetz geändert wird. The law has been amended six times, the most recent changes made in 2005 (Änderung des Gentechnikgesetzes, BGBl. I Nr. 127/2005).

8 Loi no 2004-800 relative à la bioéthique of 6.08.2004. The law has recently been revised in accordance with a "revision clause" foreseen in the Act itself. The new Loi no 2011-814 of 7.07.2011 relative à la bioéthique.

9 Gendiagnostikgesetz of 31.07.2009. Full name of the act: Gesetz über genetische Untersuchungen bei Menschen.

10 Lei no 12-2005 Informação genética pessoal e informação de saúde of 26.02.2005. Diário da República - I Série A, No 18, 26.01.2005, p. 606. A summary of the Act in: H. Nys, S. Defloor, K. Deirickx, T. Goffin, Patient Rights in the EU - Portugal, European Ethical-Legal Papers no. 13, Leuven 2008.

11 Ley 14/2007 de Investigación biomedical of 3.07.2007.

12 Loi fédérale sur l'analyse génétique humaine (LAGH) of 8.10.2004.

13 Lag 2006:351 om genetisk integritet of 18.05.2006.

14 Lov om humanmedisinsk bruk av bioteknologi (Bioteknologiloven). 
extent by a "vertical" one - in order to identify parallels and major differences between the analysed domestic regulations and international standards (especially with the IV th Additional Protocol to the European Convention on Human Rights and Biomedicine).

\section{INTERNATIONAL STANDARDS CONCERNING HUMAN GENETICS. TOOLS FOR HARMONISATION AND MEANS OF APPLICATION}

The Universal Declaration on the Human Genome and Human Rights was adopted on 11 November 199715. The following year, the United Nations General Assembly endorsed the Declaration. The Declaration has been referred to in many national and regional legislations on medicine, privacy and genetic research. UNESCO is currently evaluating the impact of the Declaration worldwide, in accordance with the Guidelines for the Implementation of the Declaration (1999). Another UNESCO document - International Declaration on Human Genetic Data was adopted unanimously on 16 October $2003^{16}$. It addresses genetic data used for medical research and a wide spectrum of other biomedical applications.

Universal documents concerning human genetics (UNESCO Declarations of 1997 and 2005) are not binding de iure, nevertheless, States agreed to see them as a benchmark (framework) for action on a national level. Implementation of Declarations can be done not only through legislative and administrative measures, but also through "soft measures", such as promotion, education, training and information dissemination.

An additional Protocol no. IV to the European Convention on Human Rights and Biomedicine concerning genetic testing for health purposes was adopted by the Committee of Ministers of the Council of Europe on 7 May 2008 and opened for signature on 27 November 2008 (hereinafter referred to as "IVth Protocol")17. Up to now, the Protocol has been ratified by three countries: Moldova, Montenegro and Slovenia, and signed

\footnotetext{
15 Text available at: http://www.unesco.org/new/en/social-and-human-sciences/themes / bioethics/human-genome-and-human-rights/ [last accessed: 14.12.2013].

16 Text available at: http://www.unesco.org/new/en/social-and-human-sciences/themes / bioethics/human-genetic-data/ [last accessed: 14.12.2013].

17 Text of the Protocol available at: http:/ / www.conventions.coe.int.
} 
by Finland, France, Iceland and Luxembourg 18 . To enter into force, five ratifications are required.

Since none of the countries under review in the article is a party to the Protocol, it is impossible to analyse and comment on its implementation and application therein. Nevertheless, the fact that an international treaty (in this case - the Protocol) has not been ratified, does not mean that national authorities should not comply with it. Since the Protocol has been adopted by the ministers representing respective states - it has legal significance. Together with respective soft law, it should be used in interpretation of domestic legal norms and serve as an inspiration for their adoption. Acknowledging a low number of ratifications of the Biomedical Convention and the IV th Protocol, the Committee of Ministers on 29 September 2010 adopted a Recommendation $\mathrm{CM} / \operatorname{Rec}(2010) 11$ on the impact of genetics on the organisation of health care services and training of health professionals, where it developed the Protocol's provisions and adviced Member States to adopt policies, legislative and other measures necessary for developing a coherent and comprehensive national policy framework for genetic services.

It is not the author's intention to analyse the provisions of the IVth Protocol in detail ${ }^{19}$. Nevertheless some general remarks about its normative character and scope should be made. Specific and technical to a great extent, the subject matter of the Protocol is reflected in the character of a state's obligations. Based on human rights standards, it is at the same time a strong instrument of harmonisation. It reflects not only principles such as the primacy of the human being over the sole interests of society or science or non-discrimination and non-stigmatisation on the ground of genetic characteristics, but also contains very precise provisions concerning the quality of genetic services and the clinical utility of genetic tests. Further cross-references to the Protocol in comparison with national laws will be made throughout the article.

18 The current state of signatures and ratifications is available at: http://www.conventions.coe.int.

19 Kapelańska-Pręgowska, supra note 3, pp. 255-284. 
Along with UNESCO and Council of Europe standards on human genetics, we can observe the continuing interest of the European Union in the matter. The European Commission proposed revision of the Directive 98/79/EC of the European Parliament and of the Council on in vitro diagnostic devices, to clarify and extend the scope of the Directive and to better regulate genetic testing within its framework ${ }^{20}$.

Moreover, on 21 May 2013, the European Commission's Joint Research Centre (JRC) published a scientific and policy report entitled Genetic Testing Offer in Europe, that covered a number of issues, such as: quality assurance (accreditation of laboratories and external quality assessment), organization of genetic testing for rare diseases in Europe and direct-to-consumer genetic testing 21 .

\section{GERMANY}

The aim and purpose of the German Law on human genetic examination (hereinafter referred to as: GenDG) ${ }^{22}$ of 1 July 2009 (in force since 1 February 2010 ${ }^{23}$ has been determined in Section $1 \S 1$ of the act. It is to set up requirements concerning "genetic examinations" and "genetic analyses". This instrumental aim is to serve the true ratio legis of GenDG - that is - prevention of discrimination and disadvantage based on genetic characteristics, protection of human dignity and the individual right to self-determination via sufficient information. The importance of the right to information (emphasised by inserting it in a provision stipulating the "Purpose of the Act"), resembles the standards of the IVth Additional Protocol and clearly shows that the German legislator attached great value to the abovementioned right.

A particular emphasis on the right to information and its very comprehensive regulation reflects the specific character of genetic tests (uncomparable - in my opinion - to other medical diagnostic tests

\footnotetext{
20 The proposed regulation is available at: http://ec.europa.eu/health/medicaldevices/files/revision_docs/proposal_2012_541_en.pdf [last accessed: 01.12.2013].

21 Text of the Report is available at: http://ihcp.jrc.ec.europa.eu [last accessed: 26.11.2013].

22 Gesetz über genetische Untersuchungen bei Menschen (Gendiagnostikgesetz).

23 BGBl. I S. 2529, ber. 3672.
} 
and procedures) and the complicated nature of their implications (not only for the person tested, but also for his or her family members).

The scope of application of GenDG covers genetic examinations and genetic analyses conducted within the framework of genetic examinations. It covers analyses conducted both on born natural persons, and on embryos and foetuses in utero. In other words, it applies to prenatal genetic diagnosis (PND), but not to preimplantation genetic diagnosis (PGD) which is performed on embryos in vitro. The Act regulates the handling of genetic data 24 and genetic samples in three contexts: for medical purposes, to determine descent, and in insurance and employment sectors, which goes beyond the scope of the IV th Protocol.

GenDG prohibits discrimination on the ground of genetic characteristics. If we compare this provision with the non-discrimination clause foreseen in the IV th Protocol, it is clear that the German legislator "went a step further" and explicitly prohibited not only discrimination on account of one's own genetic characteristics, but also based on genetic characteristics of a genetically related person. The significance and practical effect of this wider understanding of the principle of non-discrimination could particularly be observed in the context of insurance and employment.

Addressing the often expressed concerns regarding the quality and safety of genetic tests ${ }^{25}$, the GenDG - in its general provisions - sets up specific requirements and rules. Institutions that intend to perform genetic examinations (both for medical purposes and to determine descent) have to obtain accreditation (Section $1 \S 5$ ). In order to obtain it, institutions must, in particular, establish internal quality assurance procedures, employ staff qualified to perform the respective activities, set up rules for retention and destruction of the results of genetic examinations and samples (in accordance with $\S 12$ and 13 of the act), and demonstrate successful

\footnotetext{
24 Genetic data has been defined in the Act as "any data in regard to any genetic characteristic gained via genetic examination or via genetic analysis conducted in the framework of a genetic examination" (Section $1 \S 3$ ).

$25 \mathrm{WHO}$, Quality and Safety in Genetic Testing: An Emerging Concern, available at: http://www.who.int/genomics/policyquality_safety/en.index.html [last accessed: 26.11.2013].
} 
participation in external quality assurance programmes. A licence can be granted for a period of 5 years.

One of the major problems to be addressed by the law is direct-toconsumer genetic testing (DTC tests) ${ }^{26}$. These tests are not prescribed by a doctor and can be accessed via the Internet or directly from a pharmacy. The IVth Additional Protocol sets up an individual medical supervision requirement. It is subject to exceptions - if foreseen by national law.

Although the GenDG does not explicitly prohibit DTC genetic testing, it is de facto precluded, because in Section $2 \S 7$ it provides that diagnostic genetic examinations may only be conducted by a medical doctor. Moreover, the Act requires a certified specialist in human genetics to perform predictive genetic examinations. Genetic samples taken from an individual by the doctor may be analysed either by the responsible doctor himself or in the institutions (laboratories) commissioned by the doctor. Therefore there are no exceptions to the medical supervision rule.

GenDG sets up very detailed requirements regarding consent. Its provisions were clearly inspired by the work of CDBI and the IVth Additional Protocol, but again, the Act is more coherent and comprehensive than international standards. Firstly, GenDG explicitly requires consent, not only to conduct genetic examination or analysis, but also to take a genetic sample (Section $2 \S 8$ ). The similar provision on consent in Article 9 of the IVth Protocol does not mention the second element. It may nevertheless be argued that consent to take a sample (in order to analyse it later on), was implicit.

The form of consent is regulated in GenDG and IVth Protocol in a similar way. Both documents provide that it has to be informed

\footnotetext{
${ }^{26}$ Kapelanska-Pregowska, supra note 3, pp. 287-292; Ch. Patch, J. Sequeiros, M.C. Cornel, Genetic Horoscopes: Is It All in the Genes? Points for Regulatory Control of Direct-to-Consumer Genetic Testing, European Journal of Human Genetics 2009, vol. 17, pp. 857-859. The issue has also been a subject of numerous opinions adopted by international and national ethics committees and advisory bodies - see i.a.: Human Genetics Commission (UK), More Genes Direct. A Report on Development in the Availability, Marketing and Regulation of Genetic Tests Supplied Directly to the Public, 2007 or Comité Consultatif de Bioéthique (Belgique), Avis no 32 du 5 julliet 2004 relatif à la libre disposition des tests génétigues.
} 
and written ${ }^{27}$, and may be revoked at any time. It should be emphasized that GenDG also determines the content of the consent. Thus, when deciding upon a specific scope of genetic examination, the person in question has to in advance specify if, and if so to what extent, the results of an examination may be disclosed or destroyed. Conducting a genetic examination without consent is subject to criminal sanctions (maximum imprisonment sanction up to one year or a corresponding fine).

Another element of convergence between GenDG and the IVth Protocol is the limited acceptability of performing genetic tests on persons unable to express consent ${ }^{28}$. Both documents set up a rule, that a genetic test may only be performed if it could bring direct benefit to the person concerned (in other words, when it is indispensable to avoid, prevent or treat a genetically-caused illness). According to GenDG, another three requirements have to be met in order to perform a test: (1) the examination procedure has to be explained to the subject person in a manner that is as understandable as possible, and this person has not declined the taking of the necessary genetic samples; (2) the examination poses as few risks and burdens as possible; (3) the person's representative has supplied the necessary consent (subject to all requirements provided for in the act) ${ }^{29}$.

Both the IVth Protocol and GenDG foresee an exception from the abovementioned rule - when a genetic test is to be performed for the benefit

\footnotetext{
27 The Protocol does not require written form in case of diagnostic tests. Consent to predictive tests has to be documented.

28 It should be noted, that the concept of lacking the capacity to consent in a medical context is generally (in international biomedical law and domestic laws) not linked to legally determined legal capacity to act. The German Act defines, that a "person lacking the full capacity to consent" is a person who does not possess the capacity to recognize the nature, meaning or scope of a genetic examination, and is therefore unable to adjust his or her will accordingly ( $\$ 14)$. Thus, it might apply to adults (not formally incapacitated), whose perception is temporarily limited because of trauma, or to some elderly persons. On the other hand, it might not apply to some minors (who, according to domestic law, do not have a full legal capacity).

29 In its recent Opinion, Ethikrat recommended inserting clear restrictions to the Act, in order to avoid superfluous genetic information in case of tests conducted on minors (p. 160). This recommendation was inspired by the rapidly growing quantity of collectable genetic information and so-called secondary findings. It is advisable to protect the interests of persons incapable of giving consent (especially minors) from excessive information derived from tests.
} 
of others. While the Protocol allows testing for the benefit of family members (Article 13), GenDG provides for a much more limited exception. Genetic examination may only be undertaken in the case of a planned pregnancy, when it is the only way to determine whether a certain genetically-caused illness or health condition will appear in the offspring of a person genetically related to the individual lacking capacity to consent ${ }^{30}$. This exception has been criticised in the literature as grossly inequitable, since the risk to the relatives is not outweighed by an attendant benefit to the test subject ${ }^{31}$. Testing persons not able to consent (especially minors) for the benefit of others is a highly controversial issue. Even though the Protocol sets up several conditions in order to limit this possibility and to protect the person concerned ${ }^{32}$, intrusion into the person's privacy and autonomy is still very serious. If we look at the problem from another perspective, neither the Protocol nor national laws provide for an exception in the case of persons capable of consenting - even in case of serious diseases, where no alternative measures are possible to obtain health information. The German exception covering only instances of important implications for procreation choices, it seems, cannot be judged as unreasonable. It reflects a problem of many families - when a child has already been born with a genetic disease, and its parents want to determine the probability that future children will be affected with the same disease.

Another element precisely regulated in GenDG is information that has to be provided to the person concerned. This legislative thoroughness again reflects specific problems raised by genetic testing. Taking into account: a great variety of genetic tests, the difficulty in proper interpretation of their results, and the serious implications (of at least some tests), the significance of information cannot be underestimated. Of course, information is a conditio sine qua non of a valid consent to every medical

\footnotetext{
30 The exception will therefore not apply between the spouses/partners, because they are not genetically related.

31 B.P. Harbuck, Lessons for the Germany's Gendiagnotikgesetz from Europe's Protocol on Genetic Testing for Health Purposes, Washington University Global Studies Law Review 2011, vol. 10, p. 389.

32 Article 13 enumerates six conditions. According to one of them the expected benefit has to be independently evaluated as substantially outweighing the risk for private life that may arise from the collection, processing or communication of the results of the test.
} 
intervention. § 9 of GenDG provides that information should include the nature, meaning and scope of a genetic examination. More specifically, the duty to inform should cover the following elements: (1) clarification in regard to the purpose, type, scope and significance of the genetic examination, (2) clarification of any health risks for the subject person (or, if prenatal testing is to be performed - clarification of any risks to the embryo or foetus) in relation to gaining knowledge of the results of the subject genetic examination or gaining genetic samples, (3) clarification as to the intended use of any genetic samples as well as the results of any genetic examinations or analyses, (4) clarification of the right of any subject person to revoke his or her consent at any time, (5) clarification in regard to the right not to know the results of the examination (including the right to have the data partially or wholly destroyed). The content of information must be documented. Moreover, the Act requires that the person interested must receive sufficient time for consideration before the decision is made.

In a recent Opinion on the future of genetic diagnosis, the German Ethics Council recommended that an amendment be made to GenDG, clarifying that information and counselling ought to be conducted face-to-face. The Council's aim is to assure that handing out written materials is insufficient ${ }^{33}$. This recommendation is definitely a valid one, as it is a usual practice in health-care settings to provide information in a written form.

According to GenDG, rules governing genetic counselling prior to examination differ, depending on the type of genetic test ( $\S 10$ ). As for a diagnostic examination, counselling must be offered, if it concerns an untreatable disease; otherwise, counselling is optional. As for a predictive test, counselling shall be offered on a case-by-case basis under the condition that the person interested did not waive counselling in writing. This provision might be seen as purely technical (procedural), but in my opinion, an opt-out clause protects patients' interests better, than an opt-in mechanism. GenDG not only determines these basic principles, but also precludes a minimum content of counselling. It thus should include a thorough explanation of possible medical,

33 Ethikrat OPINION, supra note 5, p. 160. 
psychological, and social issues which may arise, if the examination is or is not carried out. Moreover, the doctor conducting the counselling shall inform the person concerned of possibilities of support in case of any psychical or psychological difficulties.

Since genetic information is shared within a family (relatives bound by blood ties), another issue that has to be reflected upon and regulated is informing the subject person of the possibility that test results may have important implications for family member(s), and of the subsequent procedure of passing this information to them.

In GenDG, the duty to inform a subject person is foreseen even before the genetic examination is conducted, in the course of genetic counselling. If it is suspected, that genetic relatives to the person (or embryo or foetus) concerned carry the same genetic characteristic (but only when it is correlated with an avoidable or treatable disease or health condition), counselling shall include a recommendation that such relatives should also undergo genetic counselling. Recently, the German Ethic Council rejected a proposal to introduce an independent right of the doctor to inform relatives of the patient of their genetic risk or to recommend them to obtain genetic counselling. In a conflict situation, the criminal defence of necessity (Section 34 of the Criminal Code) provides for a legal basis for the doctor to intervene to protect elementary third-party interests ${ }^{34}$.

Rules governing the reporting of the results of genetic examinations and analyses are a logical consequence of provisions regulating genetic counselling and of the medical doctor reservation principle. A general rule stipulated in $\S 11(1)$ GenDG determines, that the results of any genetic examination may be disclosed only to the person concerned and by the responsible medical doctor (that is, the one who conducted or commissioned the examination), or by the doctor who conducted genetic counselling. This provision therefore confirms the ban on direct-to-consumer testing. Parts 3 and 4 of $\S 11$ repeat provisions on consent and give a reminder that the results of an examination (analysis)

34 Ibidem, p. 162. 
may only be disclosed to the person concerned if an express and written consent was given, and, if the person so wishes, they shall be destroyed ${ }^{35}$.

Even though GenDG does not contain a general provision formulating a right to protection of privacy or of genetic data, it includes rules concerning retention and destruction of both genetic data (results of genetic examinations), and samples ( $\$ 12$ and 13 GenDG). The Act provides that results of genetic examinations must be retained for 10 years, afterwards, they must be destroyed. Destruction of data before or after that period of time is possible if the person concerned so decides. As for the genetic samples - they must immediately be destroyed if they are no longer required for the purpose for which they have been gained. Two exceptions to the rule apply: when another use is permitted by law or when the person concerned gave an informed and written consent to it.

\section{SWITZERLAND}

In Switzerland, genetic testing is regulated by the Federal law on genetic analysis (hereinafter referred to as: LAGH) ${ }^{36}$ of 8 October 2004 (in force since 1 April 2007) ${ }^{37}$. Its scope of application is wide, and similarly to the German GenDG, it covers not only testing for medical purposes, but also testing in other contexts: for identification 38 , to determine descent, in the insurance and employment sectors. Similarly to GenDG, LAGH does not cover genetic analyses performed in scientific research and in criminal proceedings ("DNA fingerprinting"). The general aim of the Act is to protect human dignity and personality, protect genetic data and to ensure the quality of genetic testing as well as its proper interpretation (Article 2).

The second chapter of the Act includes provisions common for all contexts (uses of genetic tests). In Article 4 it forbids discrimination

\footnotetext{
35 Some Authors present an opinion that GenDG sets the right to know test results above the right not to know them, which does not correspond with the IVth Protocol - see: Harbuck, supra note 22, p. 383 . I find it difficult to agree with this statement. Both documents give these rights similar value and put emphasis on the information before the person decides.

36 Loi fédérale sur l'analyse génétique humaine.

37 Act available at: http://www.admin.ch/ch/f/rs/c810_12.html. Since its adoption, the Act has not been amended.

38 With the exclusion of the indentification of missing persons, which is regulated separately.
} 
on the ground of genetic heritage (characteristics). Subsequent provisions deal with the issue of consent, a right not to know one's genetic heritage, as well as rules governing the authorisation of laboratories carrying out tests and direct-to-consumer tests.

According to Article 5, consent for a genetic test should be free and informed. LAGH does not provide for any exception from this rule, although, it might be foreseen in federal law. Consent must be express, but not necessarily written. The requirement of a written form of consent applies only to presymptomatic tests (Article 18). A person who performs a test without consent is liable to criminal sanctions (Article 36).

Article 6 of the law stipulates that a patient has a right not to be informed about his or her genetic heritage (fr. droit de ne pas être informê). Since it appears in Chapter II, it will apply in all contexts covered by LAGH. It should be noted, that the right to know and its equivalent - the right not to know, have already been recognised in international standards and domestic laws; nevertheless, only in LAGH the negative aspect of the right has been given special emphasis. This right derives from the general right to autonomy (self-determination) foreseen in Article 18. Notwithstanding its value, the right not to know is not absolute. It may be limited in the best interests of the person concerned - in case of a direct danger to the patient's life (Article 18 par. 2). Interestingly, a similar limitation does not appear in GenDG, even though it is foreseen in the IV th Protocol ${ }^{39}$.

In Switzerland, similarly to Germany, laboratories have to obtain a licence in order to carry out genetic tests (Article 8). The federal body authorised to grant licences is L'Office fédéral de la santé publique ${ }^{40}$.

As for direct-to-consumer testing, the Swiss Parliament has taken a similar position to the German Bundestag, and decided to limit access to such tests. According to Article $9 \mathrm{LAGH}$, it is forbidden to hand over

\footnotetext{
39 Article $16 \S 4$ of the Protocol stipulates that in exceptional cases, restrictions may be placed by law on the exercise of the rights contained in paragraphs 2 (right to know) and 3 (right not to know) in the interests of the person concerned.

40 Detailed provisions concerning technical and procedural matters, such as the requirements to be fulfilled by laboratories, as well as methods of supervision and monitoring are regulated in the Regulation on genetic analysis (Ordonance sur l'analyse génétique humaine - OAGH) of 14.02.2007.
} 
medical devices for in vitro diagnosis to persons who do not use them in their professional or commercial activity. Exceptionally, the Federal Council (after consulting the Commission d'experts pour analyse génétique humaine), may allow the direct offering of genetic tests to consumers, under the condition that they will be used under medical supervision and provided that there will be no danger of misinterpretation of results ${ }^{41}$.

Apart from the limitation of DTC testing, Chapter III (devoted to genetic testing for health purposes) sets up additional requirements, in order to protect patients from misunderstanding test results and taking wrong decisions. According to Article 13, genetic examination may be performed only under medical supervision. Stricter requirements apply to presymptomatic tests - for example, these tests may only be commissioned by a qualified doctor. Moreover, a doctor issuing a referral for a genetic test has to make sure that the patient has received proper counselling - both before and after a test. This requirement does not apply to diagnostic tests.

Genetic counselling should include a wide range of implications connected with the genetic test. It should not be limited to purely medical analysis, but ought to cover psychological and societal consequences. The person concerned should always be given reflection time.

Both GenDG and LAGH foresee the possibility of performing a genetic test on persons not able to consent. If we compare both acts in this respect, the immediate conclusion is that the German Act sets up a narrower exception to the rule that a test may be performed only for the benefit of the person concerned - a test may be performed for the benefit of others only when it is vital for reproductive choices (in the case of planned pregnancy of a genetic relative). According to LAGH, a test may be performed if no other method exists capable of detecting a serious genetic disease or carrier status (a so-called "no alternative rule"). As a result, the circle of potential beneficiaries is much wider. LAGH in a detailed manner regulates the scope and content of information that has to be provided to the legal representative of the person concerned.

41 It should be noted, that this provision applies to all contexts, which means that the same rules are valid for tests determining descent. It is worth emphasising, because it is a common practice in many countries to offer and advertise private DNA tests to establish or deny paternity. 
When a genetic test has been carried out, the major issue that comes into play is the way its results are disclosed. Article 19 LAGH sets up a rule, that the results of a test may be revealed only by a doctor (and not by a laboratory via letter or Internet) - which is a logical consequence of the limitation of DTC testing.

According to $\mathrm{LAGH}$, results can be passed to family members, a spouse or a partner only with the express consent of the person concerned. However, the Act contains a unique exception to this rule. If in the doctor's opinion, the prevailing interests of the person(s) listed in Article 19 par. 1 require disclosure, the doctor may request a proper canton body to release him from the duty to respect medical secrecy. It is disputable, whether such intrusion into the privacy of the person tested is justified and proportional.

I stand on the position that the decision to disclose results to third persons should remain a personal one. Of course, this decision should be an informed one. Thus a responsible doctor should be obliged to inform the patient (in a comprehensible and detailed matter) of the health implications of the test results for the family member(s).

Lastly, LAGH sets up conditions for the use of genetic material. According to Article 20 of the Act, samples cannot be used for other purposes than the one they have been collected for (and consented to). Only exceptionally, genetic material may be used for research purposes, if it has been anonymised and if the person concerned (or legal representative) has been dully informed and did not oppose it.

\section{SPAIN}

Spanish Law on biomedical research (Ley 14/2007 de Investigación biomedical) of 3 July $2007^{42}$ is another example of a comprehensive piece of legislation addressing not only genetic testing, but also other biomedical dilemmas. The Act sets up i.a. a normative framework for the operation of biobanks and provides rules for conducting medical research.

42 Boletin Oficial del Estado 2007, no. 159, p. 28826. 
Genetic tests (defined in Article 46 of the Act as diagnostic, prognostic and farmacogenetic genetic analyses) are regulated in Chapter IV, which includes provisions concerning the requirements to be met by laboratories and medical professionals dealing with tests, and the rules governing access to and storage of genetic data and samples. Apart from these specific and procedural provisions, the Act sets up certain general principles that apply to the whole text. These principles are fundamental for dilemmas posed by genetic testing and include: protection of human dignity and identity, as well as protection of individual integrity and personal rights without discrimination (i.a. on the ground of genetic heritage $\left.{ }^{43}\right)$.

Article 45 of the law enumerates principles specific for genetic testing: accessibility and quality; data protection; prohibition of financial gain and commercialisation of genetic data; consent; prohibition of storing and processing of genetic data for other purposes than provided for in the Act.

The scope of the mandatory information is similar to that foreseen in the IVth Protocol and domestic laws presented in the article. In encompasses information concerning the nature and purpose of a test, subsequent access to and use of genetic data (i.a. the possibility of their destruction), the possible health implications for family members and the possibility of receiving genetic counselling (Article 47).

According to Article 48, consent to a genetic test should be explicit, specific and written. One additional issue has been regulated by the Spanish legislator (that has not been included in German and Swiss laws) - that is - the possibility of analysing genetic samples post mortem. This possibility is foreseen in the IVth Additional Protocol and is one of the exceptions from the requirement of consent.

As for the dilemma as to who should have access to genetic data, the Spanish legislator, similarly to the Swiss one, did not give the right to privacy (of the person tested) absolute priority. Article 48 of the Spanish law does not provide for a special procedure enabling a doctor to be released from professional secrecy, but stipulates that members of the biological family (los familiares biolólogicos) of the person concerned

43 See Article 6 of the Act. 
have a right to access genetic data (test results) if it has important implications for their health ${ }^{44}$.

A person who has decided to undergo a genetic test has a right not to know its results (Article 49). We could say, that this right has its well-grounded place in the canon of "genetic rights". If the patient has exercised this right, test results should be disclosed to the member(s) of his biological family (or his legal representative), if it is necessary to avoid a serious danger to his (their) health ${ }^{45}$.

Spanish law also requires appropriate genetic counselling (Article 55) ${ }^{46}$. In order to assure proper quality of genetic services (requisitos de calidad), the Act precludes that genetic tests may only be carried out in licensed centres/laboratories (Article 57), and by a qualified medical staff (Article 56).

\section{FRANCE}

Genetic testing for health purposes was regulated, together with a wide spectrum of bioethical issues in 2004 by the Law on bioethics (Loi no 2004-800 relative à la bioéthique) ${ }^{47}$. The law has recently been revised in accordance with a "revision clause" foreseen in the Act itself. The new Law on bioethics of 7 July 2011 (Loi no 2011-814 relative à la bioéthique $)^{48}$ authorised ratification by France of the European Convention on Biomedicine and Human Rights. It consists of 11 chapters (titres) and amendments i.a. the public health code (Code de la santé publique, further: c.s.p.) and Penal code (Code pénal). Genetic tests are regulated in Chapter 1 of the law, entitled "Examination of genetic

\footnotetext{
44 It should be emphasised, that the Act uses the term "biological family", which clearly excludes other members of the broadly understood family (such as spouse, in-laws etc.) from the right to access test results.

45 This situation could be illustrated by a following example: a test has been performed on $\mathrm{Mr} \mathrm{X}$ who wished not to know the test results. If the test detected a genetic mutation that was passed to his daughter (who is a non-symptomatic carrier) and if her children could be affected with the same mutation, it might be necessary to pass this information to her.

46 Genetic counselling has been defined in Article 3 (e) of the act.

47 Journal Officiel (JORF) No. 182, 07.08.2004, p. 14040.

48 Journal Officiel (JORF) No. 0157, 08.07.2011, p. 11826. Text of the law accessible via http://www.legifrance.gouv.fr.
} 
chacteristic for medical purposes" (Examen des caractéristiques génétiques à des fins médicales).

French law requires individual medical supervision in the case of diagnostic and presymptomatic tests, and thus bans direct-to-consumer offers of these tests. Article R. 1131-5 c.s.p. provides that the prescription of a genetic test may take place only in the context of an individual medical consultation if a patient has symptoms of a genetic disease, and in case a patient is asymptomatic, but a genetic disease has been noted in the family's medical history (personne asymptomatique mais présentant des antécédents familiaux). As for the presymptomatic tests, the law is stricter, since consultation has to be carried out together with a multidisciplinary team. It is not clear if similar requirements should apply to predictive tests since the French legislator did not explicitly refer to this type of tests in Article R. 1131-5. Answer to this question depends on the interpretation of a phrase personne asymptomatique mais présentant des antécédents familiaux.

According to Article L. 1131-2-1, genetic testing or genetic fingerprinting for medical purposes may only be carried out in medical laboratories authorised in accordance with conditions laid down by law ${ }^{49}$. The French legislator has also foreseen and regulated a situation when a genetic analysis is conducted outside France - in another EU country or a state-party to the agreement on the European Economic Area ${ }^{50}$.

The law also provides that genetic analyses and genetic fingerprinting for medical purposes may only be carried out by practitioners registered and authorised by the l'Agence de la biomédecine (Article L. 1131-3). Violation of the abovementioned articles - that is - carrying out genetic analysis without authorisation is liable to criminal sanctions (punishment)

\footnotetext{
49 Reglamentative part, Title III: Médecine prédictive, identification génétique et recherche génétique, Sub-section 3: Conditions d'agrément et d'autorisation de la pratique des examens des caractéristiques génétiques d'une personne. Paragraph 2: Conditions d'autorisation des laboratoires, Article R. 1131-13 to Article R. 1131-18.

50 "Un laboratoire de biologie médicale établi dans un autre Etat membre de l'Union européenne ou partie à l'accord sur l'Espace économique européen peut réaliser la phase analytique de l'examen des caractéristiques génétiques ou de l'identification par empreintes génétiques s'il est autorisé dans cet Etat à pratiquer cette activité, sous réserve qu'il ait adressé une déclaration si les conditions d'autorisation dans cet Etat ont été préalablement reconnues comme équivalentes à celles qui résultent du premier alinéa ou, à défaut, qu'il ait obtenu une autorisation après vérification que ses normes de fonctionnement sont équivalentes à celles qui résultent du premier alinéa".
} 
of one year imprisonment and a 15000 Euros fine (Article 226-25 of penal code).

General provisions regulating consent remained in the civil code (Article 16-10). Conducting a genetic test ${ }^{51}$ without consent is liable to criminal sanctions (punishment) of one year imprisonment and 15000 Euros fine (Article 226-25 of the criminal code). The requirements concerning consent are similar to those foreseen in the IVth Protocol and national laws analysed in the article. Consent should be express, written, and informed. The detailed scope of information is regulated in the public health code ${ }^{52}$. Prior to the written expression of consent, the person concerned has to be informed of the characteristics of the disease being sought, the means of detecting it, the degree of reliability of the analyses, as well as the opportunities for prevention and treatment. In addition, the person is informed of the modalities of genetic transmission of the disease sought and their possible consequences among family members.

Article L. 1131-1 of the public health code, in its new wording, complements the civil code and provides for an exception from a rule that consent is a conditio sine qua non for a genetic test to be carried out. Thus, in a situation when it is impossible to obtain consent of the subject person and to consult a health-care proxy (la personne de confiance) $)^{53}$, the family, or (in case of their absence) one of the person's relatives, a genetic test may be performed for medical purposes in the interest of the person concerned.

If the person concerned is a minor or an adult under guardianship, a test could be authorised by the holders of parental authority or the legal representative. In addition, the consent of a minor or an adult under guardianship shall be systematically examined, to ascertain whether he or she is fit to express his or her will and to participate in the decision.

A genetic test may only be prescribed for a minor or an adult under guardianship, if the latter or its family member can personally benefit from

\footnotetext{
51 For the purpose of the article, the term "genetic testing" is used, nevertheless it has to be noted, that French law uses a similar one - that is "examination/analysis of genetic characteristics" (l'examen des caractéristiques génétiques) comprising of analyses listed in Article R. 1131-2 c.s.p.

52 Reglamentative part, Sub-section 2: Prescription conditions, Article R. 1131-4.

53 Institution of a health care proxy is regulated in Article L. 1111-6 of the c.s.p.
} 
prompt preventive or remedial measures (Article R. 1131-5). Interestingly, the law is silent as to any additional conditions for carrying out a test on persons not able to express consent for the benefit of family member(s). At this point, French law did not reach a fair balance between individual interests and is incompatible with the IV Protocol.

Important changes in the public health code were made as for the procedure and conditions concerning disclosure of test results ${ }^{54}$. The law is very detailed and precise at this point and clearly gives priority to individual privacy and medical secrecy 55 .

The prescribing physician shall communicate the results of the examination of genetic characteristics to the person concerned or, where appropriate, to the persons mentioned in the second paragraph of Article L. 1131-1. The subject person may exercise his or her right not to know the results. In this case, and subject to the provisions of the fourth paragraph of Article L. 1111-2, this fact is recorded in writing in the medical file.

In the event of diagnosis of a serious genetic condition, unless the person has exercised his/her right not to know the results, the medical information communicated shall be summarized in a document drafted in a fair, clear and appropriate manner, signed and delivered by the doctor. Moreover, when announcing the diagnosis, the doctor should provide the patient with information concerning the existence (and even a list) of one or several patients' associations that could provide further information on the genetic condition.

\footnotetext{
54 This matter is currently regulated in Article L. 1131-1-2 (created by the Loi no 2011-814 relative à la bioéthique) and corresponding Article R. 1131-19 (Conditions de communication des résultats) of the Reglamentative part of the code.

55 This direction was suggested by the Comite Consultatif National d'Ethique pour les Sciences de la Vie et de la Santé in: Avis no 76. A propos de l'obligation d'information génétique familiale en cas de nécesité médicale, 24.04.2003, pp. 8-11. In the Committee's opinion, medical secrecy is a prerequisite of trust between a patient and a doctor. Thus, the Committee recommended that the legislation should focus on information that should be provided to the patient (of possible risks to the family member), in order to convince him or her that he or she should share it.
} 
In the event of a serious genetic condition ${ }^{56}$ - that could engage preventive measures, including genetic counselling or care - being diagnosed, the prescribing physician shall inform the subject person (prior to the completion of the analysis) of the risks that silence would have implications for the potentially affected members of his family. Moreover, the law requires the physician to prepare a written document intended for concerned family member(s).

If the person does not wish to inform the family member(s) personally, he or she may request in writing that the prescribing physician hand over this information. The doctor should only inform the family members of the existence of the medical information of a familiar character and invite them to take advantage of genetic counselling. The doctor should not disclose the name of the person tested, the genetic anomaly, nor the risks that are associated with it.

If the person has expressed in writing his or her wish to be held in the ignorance of the diagnosis (right not to know), it may allow the prescribing physician to proceed with the information addressed to the family members, under the conditions laid down by law.

Another particularity regulated by French law is disclosing test results in case the subject person donated his or her gametes or embryos. When the test concerns a serious genetic condition susceptible of preventive measures, the person may authorize the prescribing physician to hand over the information to the fertility centre.

Recently, sub-section 6: Conditions of implementation of the information to the relatives (Conditions de mise en auvre de l'information de la parentèle) was added to the regulatory part of the public health code by the Décret $n^{\circ} 2013-527$ du 20 juin 2013 relatif aux conditions de mise en œuvre de l'information de la parentèle dans le cadre d'un examen des caractéristiques génétiques à finalité médicale. This regulation further particularizes provisions of the Legislative part of the code.

56 Good practices concerning i.a. the criteria to identify serious diseases caused by genetic mutations will be defined by decree of the Minister of Health based on the proposal made by l'Agence de la biomédecine and Haute Autorité de Santé (Article R. 1131-20-5). 
According to its provisions, if it is suspected that a person is affected with a genetic characteristic responsible for a serious medical condition/disease (une affection grave) susceptible of preventive measures (including genetic counselling or care), the prescribing physician shall inform (prior to the prescription) the person tested, that it is required (if the diagnosis of this anomaly is confirmed) that the concerned family members or their legal representatives be informed.

In accordance with the provisions laid down in Article L. 1131-1-2, the doctor shall also inform the person tested that, in case he or she express in writing his or her willingness to be kept in ignorance of the diagnosis (right not to know) or does not wish him or herself to inform the concerned family members or some of them, the person may authorize proceeding with this information under the conditions provided for by law and by the present sub-section.

The prescription and information procedure will be different in a case in which there is a high probability that the information could only be used in the context of a parental project (in other words, for procreation choices). In this event, the person concerned shall be directed to a doctor operating within a multidisciplinary team mentioned in the second paragraph of Article R. 1131-5.

Furthermore, the law in a detailed manner regulates the preparation of the written information document mentioned in the first paragraph of Article L. 1131-1-2. The prescribing physician has to determine who shall be informed and to what extent. Thus, taking into account medical evidence available to him at this stage, and in accordance with the best practices defined by Article R. 1131-20-5, the doctor determines the categories of family members potentially concerned, having regard to the relationship with the person tested and the nature of the anomaly sought.

If the person tested expresses his or wish to directly inform the concerned relatives (or some of them), the prescribing physician should document it in the medical file and specify the identity of the third party who will be informed. If the person concerned expressed the opposite wish or exercised its right not to know the test results, the person will have to decide if he or she agrees that the information 
be passed on by the prescribing physician. Both consent and refusal have to be documented in the medical file.

The information is passed by a doctor according to the procedure provided for in the fourth paragraph of Article L. 1131-1-2 - that is via a registered letter informing the recipients of the existence of medical information likely to affect them ${ }^{57}$. The law further provides that in the event that the person(s), who received the abovementioned letter, consult(s) a doctor, the doctor is required to contact the prescribing physician to obtain the information relating to the genetic anomaly in question. Apart from that information, the prescribing physician cannot disclose any other data covered by medical confidentiality, especially the identity of the person who has been tested.

\section{SUMMARY}

The analysed domestic laws regulating genetic tests largely correspond with the relevant international standards, even though none of the countries under consideration in the article is a party to the Protocol. Its provisions clearly guided and inspired law making processes in Germany and France.

Comparative analysis highlighted similarities, differences, strengths and weaknesses of the existing laws. The conclusions below may serve as a starting point and some guidance for law-makers in the countries, where - as in Poland - no specific regulations were adopted.

All legislations put emphasis on the quality of genetic services and the appropriate education of specialists. They all require accreditation of laboratories/centres to carry out tests. The answer to another disturbing problem - direct-to-consumer genetic tests - is again similar. In the countries under review, an individualised medical supervision reservation exists, which means that a genetic test may only be carried out by a medical doctor (after proper information has been given to the person concerned and usually after genetic counselling) ${ }^{58}$.

\footnotetext{
57 A model of a letter is determined by order of the minister responsible for health.

58 P. Borry et al., Legislation on Direct-to-Consumer Genetic Testing in Seven European Countries, European Journal of Human Genetics 2012, vol. 20, pp. 715-721.
} 
The correct interpretation of results and the guarantee of appropriate genetic counselling to understand their implications remain the main concern. It is believed, in this respect, that these conditions cannot be satisfied outside of individualised medical supervision ${ }^{59}$. Notwithstanding their concerns, the IVth Protocol left a certain margin of appreciation in deciding whether all types of tests should be covered by this reservation ${ }^{60}$. The problem of DTC tests is undoubtedly a difficult one, especially because more tests are being offered on the Internet. Here, along with regulatory measures, public education programmes should be introduced 61 .

Notwithstanding a general positive assessment of national laws presented in the article, some inconsistencies and controversial points could be found. Comparison of the four legislations allow for a conclusion that domestic regulations cover all major points (which proves, that legislators are aware of the most problematic issues), but differ in several specific areas.

Still, national laws do not always accurately reflect the fact that different types of genetic tests cause different medical, ethical and legal dilemmas. It is a fundamental mistake to regulate "genetic tests" or "genetic analyses" as such, without targeting specific needs and problems. This lack of clarity is especially evident in the French regulations. Thus, de lege ferenda, a good starting point would be to include legal definitions of tests within the acts.

Another issue, reflected both in the IV th Protocol and in national laws, but differing in detail, is testing persons not able to consent ${ }^{62}$. Conditions set up in German GenDG correspond to the Protocol to the greatest extent. Most evident differences may be observed with respect to the possibility of conducting a test for the benefit of family members. Balancing individual

\footnotetext{
59 Explanatory Report to the Protocol, par. 70. Available at: http:/ /www.conventions.coe.int. 60 Its Article 7 provides that exception to the rule cannot be made only in the case of genetic tests with important implications for the health of the person concerned or of members of his or her family, or for choices concerning procreation.

61 Ethikrat OPINION, supra note 5, p. 157.

62 It might become one of the major bioethical problems in the future, because obtaining a biological sample is non-invasive and can be done not only without consent of the person concerned, but also without his or her knowledge.
} 
interests in this context will undoubtedly remain a "hard regulatory nut to crack".

Lastly, all four laws address one of the major concerns connected with the hereditary character of most genetic diseases - that is - the question of revealing the tests results to family members. In this context, law-makers have once more to weigh competing interests, and decide on the scope of the "duty to warn" and potential exceptions to medical secrecy63. Here again, different choices as for the specific conditions and procedures were made 64 .

63 For overview of the problem see i.a.: K. Offit et al., The "Duty to Warn" a Patient's Family Members About Hereditary Disease Risk, Journal of American Medical Association 2004, vol. 292, no. 12, pp. 1469-1472; N.F. Sharpe, R.F. Carter, Genetic Testing: Care, Consent and Liability, New Jersey: John Wiley \& Sons 2006, p. 403 et seq.

64 Explanatory Report to the IVth Protocol leaves the margin of appreciation to the states in this respect and includes some suggestions: For the communication of this information to the family members, appropriate provisions should be made, bearing in mind the rules on confidentiality and the protection of the private life of the various persons concerned (person on whom the test is performed and members of his or her family). The choice of procedure(s) is left to the States. If the person tested is unable or unwilling to contact his or her family members directly he or she may be given appropriate material or letters to pass on to the family member(s). Consideration could be given to setting up a mediating body responsible for contacting family members of the person concerned if the latter has asked for them to be informed without him or herself being identifiable as the source of the information. Another example, would be the possibility to provide for a decision by a competent body, following comparative assessment of the respective interests of the persons concerned, on whether or not the information in question must be communicated to the members of the family (par. 140). 
